IZA DP No. 10210

If Life Throws You Lemons, Try To Make Lemonade: Does Locus of Control Help People Cope with Unexpected Shocks?

Steven Stillman

Malathi Velamuri

September 2016 


\title{
If Life Throws You Lemons, Try To Make Lemonade: Does Locus of Control Help People Cope with Unexpected Shocks?
}

\author{
Steven Stillman \\ Free University of Bozen-Bolzano \\ and IZA \\ Malathi Velamuri \\ Chennai Mathematical Institute
}

Discussion Paper No. 10210

September 2016

\author{
IZA \\ P.O. Box 7240 \\ 53072 Bonn \\ Germany \\ Phone: +49-228-3894-0 \\ Fax: +49-228-3894-180 \\ E-mail: iza@iza.org
}

\begin{abstract}
Any opinions expressed here are those of the author(s) and not those of IZA. Research published in this series may include views on policy, but the institute itself takes no institutional policy positions. The IZA research network is committed to the IZA Guiding Principles of Research Integrity.

The Institute for the Study of Labor (IZA) in Bonn is a local and virtual international research center and a place of communication between science, politics and business. IZA is an independent nonprofit organization supported by Deutsche Post Foundation. The center is associated with the University of Bonn and offers a stimulating research environment through its international network, workshops and conferences, data service, project support, research visits and doctoral program. IZA engages in (i) original and internationally competitive research in all fields of labor economics, (ii) development of policy concepts, and (iii) dissemination of research results and concepts to the interested public.
\end{abstract}

IZA Discussion Papers often represent preliminary work and are circulated to encourage discussion. Citation of such a paper should account for its provisional character. A revised version may be available directly from the author. 
IZA Discussion Paper No. 10210

September 2016

\title{
ABSTRACT
}

\section{If Life Throws You Lemons, Try To Make Lemonade: Does Locus of Control Help People Cope with Unexpected Shocks?*}

\begin{abstract}
A number of recent papers have found that non-cognitive skills and in particular, locus of control (LoC), are important predictors of success in life in terms of both traditional labor market and socioeconomic outcomes, and measures of subjective wellbeing. Specifically, the literature has found a strong correlation between having an internal locus of control and standard measures of success and happiness. In this paper, we examine whether having an internal LoC also helps people manage the consequences of two mainly unanticipated negative shocks, being a crime victim and experiencing a serious illness or injury. We find that these events have large negative consequences on both subjective wellbeing and objective economic outcomes. For men, these shocks have smaller effects on subjective wellbeing when they are more internal but that the long-run effects on income are no smaller. On the other hand, for women with an internal LoC, we find some evidence that these shocks have larger impacts. We draw on the psychology literature to discuss the results.
\end{abstract}

JEL Classification: $\quad 131, \mathrm{~J} 16$

Keywords: $\quad$ locus of control, crime, illness, wellbeing, HILDA

Corresponding author:

Steven Stillman

Department of Economics and Management

Free University of Bozen-Bolzano

Piazza Università 1

Bozen-Bolzano, 39100

Italy

E-mail: steven.stillman@unibz.it

\footnotetext{
* This paper uses unit record data from the Household, Income and Labour Dynamics in Australia (HILDA) Survey. The HILDA Project was initiated and is funded by the Australian Government Department of Social Services (DSS) and is managed by the Melbourne Institute of Applied Economic and Social Research (Melbourne Institute). The findings and views reported in this paper, however, are those of the author and should not be attributed to either DSS or the Melbourne Institute.
} 


\section{Introduction}

A number of recent papers have found that non-cognitive skills and, in particular, locus of control, are important predictors of success in life in terms of both traditional labor market and socioeconomic outcomes and measures of subjective wellbeing (Heckman et al. 2006; Cobb-Clark and Schurer 2013; Coleman and DeLeire 2003). Locus of control (LoC) represents a person's feeling about how much control they have over their life (Rotter 1966; Gatz and Karel 1993). People with 'internal' LoC believe that much of what happens to them is caused by their own actions, while those who are 'external' believe forces beyond their control are the main determinants. The literature has found a strong correlation between being internal (that is, having an internal LoC) and standard measures of success and happiness (Heckman et al. 2006; Cobb-Clark and Schurer 2013; Coleman and DeLeire 2003).

In this paper, we examine whether being internal also helps people cope with the consequences of two mainly unanticipated negative shocks: being a crime victim and experiencing a serious illness or injury. ${ }^{1}$ As is shown in this and other recent papers, these events have large negative consequences on both subjective wellbeing and objective economic outcomes (Mahuteau and Zhu 2015; Ballas and Dorling 2007; Powdthavee 2009; Frijters et al. 2011; Johnston et al. 2015). We choose to examine these two events because in the data we use, the Household Income Labour Force Survey of Australia (HILDA), they are two of the more common negative shocks that the previous literature suggests are both mainly unanticipated and have large negative impacts. ${ }^{2}$ HILDA is a longitudinal study, hence we are able use an individual fixed effects approach to control for all time-invariant confounding factors in the relationship between these shocks and the outcomes we examine, as well as for all fixed cognitive and non-cognitive skills.

\footnotetext{
${ }^{1}$ There is evidence from psychologists suggesting that personality traits influence an individual's likelihood of experiencing specific life events as well as their speed of adaptation (Mazure et al., 2000; Jakšić et al., 2012). Hence, we also examined whether there were interactions between personality traits, such as being conscientious, and the impact of these shocks. With the exception of LoC, we did not find any evidence for interactive effects for any of the other personality traits measured in the data.

${ }^{2}$ In general, there is some anticipation of these events and hence in our regression models we control for the year prior to each event occurring. However, we do not find consistent evidence that the anticipation extends further back in time, which is consistent with previous research such as Frijters et al. (2011).
} 
Psychologists view coping strategies as either problem-focused or emotion-focused. Problemfocused coping comprises efforts to alter the hostile environment that is perceived as the source of stress/shock. Emotion-focused coping, on the other hand, tries to manage or regulate the emotional responses evoked by the stressful situation. Individuals with an internal LoC are more likely to use problem-focused coping strategies relative to those who see situations as not amenable to control (Folkman, 1984; Bandura, 1992). This has led some psychologists to argue that internal people are better able to cope with negative shocks while others contend that the relationship between LoC and coping depends on the specific event (Steinlauf 1979; Greenglass 1988).

A recent paper by Buddelmeyer and Powdthavee (2016) also examines the role of internal LoC in moderating the impact of negative shocks using the HILDA data, using methods similar to those used in this paper. ${ }^{3}$ We compliment and extend upon this paper in a number of dimensions. First, we focus only on the two shocks discussed above, while they examine the impact of a wide range of negative shocks measured in HILDA including many that are likely to be strongly anticipated (e.g. being fired, separating from a spouse) and some that likely confound a number of shocks (e.g. major worsening in finances, death of a family member). By focusing on just two shocks, we are able to delve more deeply into important heterogeneity in response to these shocks. Along these lines, our second major contribution is that we examine the impact of these shocks and the moderating influence of LoC on multiple measures of affective wellbeing, cognitive wellbeing and traditional socioeconomic outcomes, while they just consider the impact on one outcome from each wellbeing domain (mental health and life satisfaction).

Psychologists categorize subjective wellbeing (SWB) into two distinct components: (1) affective wellbeing (AWB), which reflects positive (eg., happiness) and negative (eg., depression) emotions and moods, and (2) cognitive wellbeing (CWB) that relates to how individuals evaluate their life overall (life satisfaction, for example) as well as specific life domains (job satisfaction, satisfaction with relationships etc.). ${ }^{4}$ AWB serves an information function in that emotions and moods are seen as internal monitors of progress towards goals. To maintain this functionality, AWB is required to adapt quickly to long-term changes (Kim-Prieto et al., 2005). Life events are likely to affect

\footnotetext{
${ }^{3}$ Etilé et al. (2014) has some similarities to our paper as well but focuses on the role of early childhood circumstances in moderating the impact of negative shocks on mental health.

${ }^{4}$ See Luhmann et al. (2012) for a detailed description of the AWB and CWB constructs.
} 
CWB significantly if they are perceived as impeding major life goals either in the work sphere or in the family/relationship sphere (Wilson and Gilbert, 2008). Changes in CWB are hypothesized to be less automatic compared to changes in AWB. Consistent with this theory, evidence indicates that positive income shocks increase life satisfaction but do not have much impact on emotional wellbeing (Kahneman and Deaton, 2010). Thus, prior evidence suggests that adaptation of AWB and CWB may not occur at the same rate. This is precisely what we find in our empirical results.

Finally, we carefully look at heterogeneity by gender. A number of early studies found that the distribution of scores on Rotters internal-external (IE) scale test differed between the genders, with women obtaining higher external scores on average. ${ }^{5}$ Evidence from psychologists also reveals gender differences in coping with life events (Carver et al., 1989; Lengua and Stormshak, 2000). Our main findings discussed below are consistent with the patterns emphasized by the psychology literature and reveal the importance of looking at men and women separately.

Using eleven years of longitudinal data from HILDA and allowing for a flexible adaptation profile, we find notable gender differences in response to shocks as well as in adaptation. For men, we find that being the victim of a crime or suffering from a serious illness or injury has smaller effects on subjective wellbeing when they are more internal. This is true for both AWB and CWB, but stronger for AWB as measured by the SF-36 mental health domain. On the other hand, while both negative shocks lead to large long-run declines in income, this is not smaller for more internal men. Hence, it appears that men who are more internal feel better about similar circumstances than those that are more external.

For women, we find evidence that an internal LoC can be bad for coping. For example, being the victim of a violent crime has larger negative impacts on AWB and socioeconomic outcomes (in particular, marital status) for women that are more internal. This is also true for short-run impact of a serious illness or injury on physical health. In some circumstances, it appears to be easier for women to cope with unexpected negative shocks if they feel circumstances are outside their control. The rest of the paper is organised as follows: section 2 describes the data used in the analysis and presents some descriptive statistics. We present the empirical strategy in Section 3 and results in Section 4. Section 5 concludes.

\footnotetext{
${ }_{5}^{5}$ See Randall and Desrosiers (1980), Strickland and Haley (1980) and references therein.
} 


\section{Data and Summary Statistics}

HILDA began in 2001 and has since been administered annually. HILDA interviews all adult members (aged 15 and over) in over 7,500 sample households and collects information about economic and subjective wellbeing, labour market dynamics and family dynamics. Individuals in sample households are followed over time regardless to whether they remain in the original households. Four survey instruments are included in HILDA: a Household Form and a Household Questionnaire are completed during a personal interview with one adult member of each household; a Person Questionnaire is administered to all adult household members; and a Self-Completion Questionnaire (SCQ) is provided to all respondents to the Person Questionnaire and is collected at a later date or returned by post.

The SCQ elicits subjective responses to an array of sensitive questions. Starting in the second wave (2002), the following question was added to the SCQ: "We now would like you to think about major events that have happened in your life over the past 12 months. For each statement cross either the YES box or the NO box to indicate whether each event happened during the past 12 months. If you answer YES, then also cross one box to indicate how long ago the event happened or started." Twenty-one major events are then listed below the question. We focus on two of these events, 'Victim of physical violence (e.g., assault)' and 'Serious personal injury or illness to self'. As discussed above, we focus on these events because they are fairly common, less likely to be anticipated than some of the other events captured in this survey and have been found to have large impacts on individual outcomes. Unfortunately, individuals do not provide any further details about any of the events listed in this section.

The SCQ also includes the standardized SF-36 questions on the health domains of physical functioning, role-physical, bodily pain, general health, vitality, social functioning, role-emotional and mental health. These questions can be aggregated to form standardized scores for general physical and mental health domains, valued from 0 to 100. We examine the impact of shocks on both of these. The mental health domain can be viewed as an AWB measure, since it includes questions such as whether the individual was happy, whether the individual was depressed and so on during the 4 weeks prior to the survey. Our outcome measures also include individuals' reported over- 
all life satisfaction, ${ }^{6}$ which reflects cognitive wellbeing (CWB). We include a second measure of CWB, an individual's average satisfaction with their relationships. ${ }^{7}$ We also consider three objective, domain-specific measures of CWB, specifically employment status and personal income (job domain) and marital/de-facto relationship status (relationship domain).

Locus of control is measured in HILDA in the 2003, 2004 and 2007 waves. A module of seven questions is asked where each is in the form of statements asserting a higher or lower degree of autonomy over one's life. ${ }^{8}$ Respondents are required to agree or disagree with each assertion. Following the literature, we reverse coded the responses to some statements such that for all responses, a higher number implies greater internal LoC. For each of the three waves, we then added these responses to get a range from 7-49. We then standardized this index over the entire sample. Thus, a positive (negative) index value implies an internal (external) LoC relative to the mean. Cobb-Clark and Schurer (2013) found that the LoC is stable in response to the same shocks we examine here but contains a significant amount of classical measurement error. For this reason, we average the index over all available waves for each individual to create a time-invariant measure of LoC.

We use data from the 2002 to 2011 waves of HILDA as the question on experiencing shocks was added in 2001. We initially restrict our sample to 102,025 observations where individuals are aged 25-64, are not Aboriginal/Torres Straight Islanders and did not join HILDA in the wave 11 booster sample. We then further drop 19,162 observations where the shock data is unavailable, 7,558 observations where individuals experienced one of the shocks in their first year in the data

\footnotetext{
${ }^{6}$ The person questionnaire asks a series of questions on eight different aspects of life satisfaction in each wave. Individuals are then asked, "All things considered, how satisfied are you with your life? Again, pick a number between 0 and 10 to indicate how satisfied you are." This is the measure we use of overall life satisfaction.

${ }^{7}$ Individuals are asked to rank, again on a 0 to 10 scale, how satisfied they are with their relationship with their partner/spouse, children, stepchildren, parents, stepparents, and most recent former spouse/partner, their partner's relationship with their children, and their children's relationship with each other. Because not all of these relationships are applicable for each person, we average over all that apply to each person to create a measure of each individual's average satisfaction with family relationships.

${ }^{8}$ The statements are: (1) "I have little control over the things that happen to me"; (2) "There is really no way I can solve some of the problems I have"; (3) "There is little I can do to change many of the important things in my life"; (4) "I often feel helpless in dealing with the problems of life"; (5) "Sometimes I feel that Im being pushed around in life"; (6) "What happens to me in the future mostly depends on me"; (7) I can do just about anything I really set my mind to do". Each is on a scale of 1-7, with higher numbers indicating more agreement.
} 
(and hence do not have a pre-shock observations), 1,730 where individuals did not answer the LoC questions at least once, 3,098 observations where at least one of the outcome variables was missing and 928 observations where individuals were only in the sample for one wave. Our resulting analysis sample includes 69,549 observations on 9,745 individuals. Table A1 in the appendix presents the characteristics for individuals in the analysis sample and excluded population. The distribution of most background characteristics (age, qualifications, employment status, income and location) is quite similar for the analysis sample compared to the overall prime-age population.

Table 1 presents summary statistics for the analysis sample, categorized first by gender and subsequently by whether a shock was ever experienced. While women are slightly more likely to have been victims of crime, there are no differences with regard to experiencing illness/injury, and to experiencing both types of shocks. For both men and women, there is some evidence of negative selection; labor-market outcomes and marital rates are markedly lower, relative to non-victims. These differences are especially pronounced in the case of crime victims. Differences by educational attainment are more ambiguous; shocks victims have higher rates of non-university degrees but lower rates of bachelors or higher degrees. Individuals who experienced either type of shock have lower subjective wellbeing (health and satisfaction) relative to those who did not experience either shock. However, this could be a consequence of a sharp deterioration in these outcomes following the shock. Differences in locus of control (LoC) are notable; shocks victims have lower LoC implying a greater external LoC. Moreover, women who experienced shocks have much lower LoCs compared to their male counterparts. Thus, the summary statistics provide some evidence that those who experience negative shocks have different characteristics and outcomes compared to those who did not experience either type of shock. It will therefore be important to control for this heterogeneity in a regression analysis.

\section{Empirical Strategy}

We follow the established literature and estimate a flexible model of the impact of each shock on each outcome, allowing for interactions between LoC and each shock measure. Consider the following linear model: 


$$
Y_{i, t}=\Sigma_{q=-3}^{1}\left(\delta_{q}^{k} S h o c k_{i t}^{q k}+\lambda_{q}^{k} S h o c k_{i t}^{q k} * L o C_{i}\right)+X_{i t} \beta+\alpha_{i}+u_{i t}
$$

where $Y_{i t}$ is one of our chosen outcomes for individual $i$ at time $t$; Shock $k_{i t}^{q k}$ is one of the two shocks examined in this paper: i) whether individual $i$ was a victim of violent crime in the previous 12 months $(k=1)$ and ii) whether s/he had a serious personal illness or injury over that same period $(k=2)$. We estimate the anticipation effect $(\mathrm{q}=1)$, and the immediate $(\mathrm{q}=0)$, short $(\mathrm{q}=$ $1)$, medium $(q=2)$ and long-term $(q=3)$ impacts of these shocks, with the anticipation effect measured the year before the event, the immediate impact defined as less than 1 year after the event, short-term as 1-2 years after the event, medium-term as 2-3 years and long-term as 4 or more years after the event. ${ }^{9} S_{h o c k}^{q k} * L o C_{i}$ is the interaction between each of the shock variables, $k$, and an individual's time invariant Locus of Control. The coefficients on these interaction terms, $\lambda_{q}^{k}$, are the main focus of our paper although we also present and discuss the coefficients on shock variables themselves, $\delta_{q}^{k}$.

All our regressions include individual fixed effects, $\alpha_{i}$, a limited set of exogenous or predetermined time-varying covariates, $X_{i t},{ }^{10}$ and a standard error term that is potentially correlated over time within individuals, $u_{i t}{ }^{11}$ Controlling for individual fixed effects is asymptotically equivalent to examining the relationship between an individual experiencing a shock and changes in an outcome for the same individual over time. ${ }^{12}$ This controls for selection on any time-invariant unobserved characteristics of individuals that are related to both their likelihood of suffering the shock and the outcome being examined. For example, individuals who have a positive outlook about life might be less likely to have an illness and to report higher levels of life satisfaction. Importantly, the fixed effect also controls for unobserved fixed cognitive and non-cognitive skills. These fixed effects estimates will be unbiased as long as there are no time-varying unobservables that are correlated

\footnotetext{
${ }^{9}$ We first allowed the impact of each shock to vary more flexibly on an annual basis and then used these results to decide how to best aggregate time periods. The end goal was to have as much flexibility in the estimates as possible while allowing for a concise summary of the findings.

${ }^{10}$ Specifically, we control for a quadratic in age and include dummy variables for statistical region, remoteness and survey year.

${ }^{11}$ In other words, our standard errors are clustered at the individual level.

${ }^{12}$ Individuals who do not experience shocks only contribute to the estimates by providing information on the link between the included covariates and the outcomes.
} 
with both the propensity of experiencing a shock and any of our observed outcomes.

In this regression model, the temporal impacts of a shock are measured relative to outcomes for the same individual in years more than one year prior to experiencing the shock. We control separately for the year prior to the event to allow for anticipation effects. Anticipation affects are likely if individuals are forward-looking and have information that allows them to predict future events with some degree of certainty. To the extent that being a victim of crime is truly random, we would expect anticipation effects to be zero for this type of event. If victimization is a consequence of domestic violence or perpetrated by an individual known to the victim, however, we cannot rule out anticipation. ${ }^{13}$ With regard to the second shock in our analysis, anticipation effects are more likely; individuals may anticipate certain types of illnesses based on knowledge of family history or events in their past that are not observed by the researcher.

\section{Results}

We begin by presenting estimates of the impact of each shock on each outcome variable without LoC interactions. As LoC is normalized to the population mean, the main effects of the regression model presented here are unaffected by the addition of the interaction term and these results allow us to then judge the size of the interaction effects. The main effects for each shock are presented in Table 2 for men and Table 3 for women. Each named row presents $\delta_{q}^{k}$, the estimated temporal coefficient, with $q=-1$ measuring the anticipation effect, $q=0$ the short-term ('Current year'), $q=1$ the medium-term ('One year later' and '2-3 years later') and $q=2$ ('4+ Years Later') for long-term impacts of the shocks ( $k=1$ for crime victimization and $k=2$ for personal illness/injury) on the particular outcome variable which is specified in the columns. All continuous outcome variables in the regression are also standardized. Thus, all coefficients can be interpreted as the impact of a particular shock on a standard deviation of the outcome variable or the change in the predicted probability of the outcome in the case of employment and marital status. All standard errors are clustered at the individual level to allow for arbitrary serial correlation in outcomes for individuals.

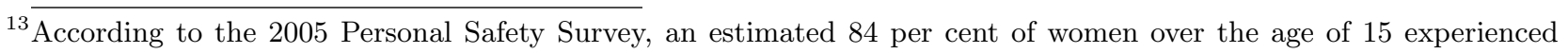
their most recent incident of physical assault by a male who was known to them (ABS, 2005). 
Estimates in Table 2 reveal no anticipation effects of violent crime victimization for men. This is consistent with the fact that perpetrators in incidents involving physical violence (which includes physical assault and sexual violence) against men are predominantly strangers. ${ }^{14}$ Crime victimization has a big impact on mental health, life satisfaction and satisfaction with relationships. On average, less than one year after the event, reported mental health and life satisfaction are lower by over one-quarter of a standard deviation (SD), and satisfaction with relationships by nearly one-fifth of an SD. None of these impacts appear to last; there is complete adaptation in all these outcomes four or more years after the event. Interpreting the mental health outcome as a measure of AWB, and life and relationship satisfaction measures as CWB measures, there is evidence of quicker adaptation of AWB, which is consistent with the psychology literature (Kim-Prieto et al., 2005).

Crime victimization also affects the propensity of being married or in a de-facto relationship. These effects are small but significant, and also disappear after four years. Interestingly, there is a lagged impact on income, which appears to strengthen with time. In fact, being a victim of a violent crime is estimated to lead to almost a .1 SD decline in income in the medium-run. This is equivalent to 5,087 in 2001 Australian dollars, a significant decline. This is possibly an indirect effect, working through the mental health channel. If that is the case, then adaptation of mental health might take considerably longer than what the direct impacts indicate.

In contrast to crime victimization, experiencing serious personal illness or injury has significant anticipation effects; there is a drop in physical and mental health equivalent to about one-twelfth of a SD for each, and a decline in life satisfaction of about one-twentieth of a SD before the occurrence of the event. This result is consistent with the evidence from the literature (Lindeboom et al., 2002; ABS, 2005; Mervin and Frijters, 2014). This implies that individuals possess information that is relevant to this particular shock but is not observed by researchers. However, these anticipation effects are small relative to the short-run impacts and do not appear more than one year prior to the event.

While the immediate deterioration in reported physical health after the onset of illness is substantial,

\footnotetext{
${ }^{14}$ For instance, according to the Australian Personal Safety Survey 2005, about $72 \%$ of violent crimes against men in the previous 12 months were committed by strangers (ABS, 2005).
} 
measuring over one-half of a SD, there is also evidence of rapid improvement; while adaptation is not complete even in the long-term (four or more years after the event), the negative impact on physical health is considerably smaller (about one-tenth of an SD) than the immediate impact. The negative and persistent impact of this event on men's life satisfaction is also notable. Consistent with the findings of Lindeboom et al. (2002), the impact of this shock is bigger on mental health (AWB domain) than on the cognitive domain. There is, however, evidence of complete adaptation in mental health in the long-run.

Outcomes related to the job domain - employment and income - reveal no anticipation effects for men. The onset of illness or the occurrence of a serious injury lowers the short-term probability of being employed by about $5 \%$. While this impact declines over time, it is persistent; the probability of employment is about $3 \%$ lower even four or more years after the event. The impact on income lags the effect on employment, is persistent, sizable, significant and increases over time. In the long-term (four or more years after the event), the decline in income measures about one-tenth of a SD on average, a substantial effect.

Table 4 presents the corresponding estimates for women, and reveals some interesting differences. The first notable difference is the substantial and significant anticipation effects of crime victimization on mental health, life satisfaction and satisfaction with relationships. Though we cannot make any strong claims without having more details about these crimes, this result is quite consistent with women victims of crime knowing their attackers (see footnote 13). The anticipation effect for mental health is about the same as the short-term impact, and in the case of the satisfaction domains, it is bigger than the respective short-term impacts. Moreover, the average impact on mental health for women is over two times that for men for each corresponding time horizon, and more persistent. On average, one year after the event, reported mental health is lower by over one-half of an SD for women. While men return to pre-event mental health levels in the medium-term, women adapt more slowly.

In contrast, while the short-term (current year) negative impact of crime victimization on overall life satisfaction and satisfaction with relationships is bigger for women, adaptation is faster. While men experience a drop in income in the medium and long-term, crime victimization appears to have no impact for women in the job domain (employment probability and income), on average. 
The negative prospects of being in a marital or de-facto relationship, on the other hand, are in general bigger and more persistent than those for men.

Women also appear to anticipate an imminent serious illness/injury, and as with men, this expectation is apparent in a decline in reported physical and mental health and overall life satisfaction in advance of the event. These anticipation effects are much bigger for women, and on average, are consistently bigger than the corresponding effects one year after the event. As with men, while the immediate impact on physical health is substantial, declining by three-fifths of a SD, there is rapid adaptation over time but the process remains incomplete even four years after the event. Taking the anticipation effect into consideration, the impact of illness on physical health is substantial. Interestingly, while women experience an immediate reduction of one-fifth of a SD in life satisfaction, they appear to adapt quickly compared to men; four years after the event, life satisfaction levels are still negative but not statistically significant. The temporal impacts on mental health are similar for both genders.

The impact of serious illness on job prospects is also similar for men and women; there are no anticipation effects, and the magnitude and persistence of the decline in job prospects are alike. Again, as in the case for men, the decline in individual income lags the employment effect but the magnitude is much smaller relative to men. Unlike men, individual income adapts completely to the illness shock for women four years after the event. This shock appears to have no impact on relationship prospects for either gender.

In Tables 4 (Men) and 5 (Women), we present the coefficients on the interaction terms on LoC from the full model described in Equation (1). As discussed above, because LoC is population standardized, the main effects are the same as those presented in Table 2 and $3 .{ }^{15}$ These coefficients can be interpreted as showing the impact of the corresponding shock on wellbeing for individuals who have a LoC that is 1 standard deviation (SD) more internal than the average person in the sample (or conversely, the negative of the coefficient indicates the impact of the event on wellbeing for individuals with an LoC that is $1 \mathrm{SD}$ more external than the average Australian). ${ }^{16}$

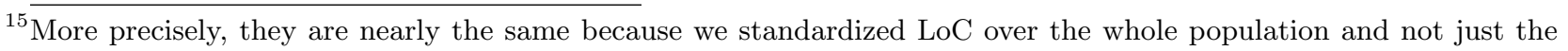
analysis sample. But, for practical purposes they are equivalent.

${ }^{16}$ We also examined how the impact of shocks varied across quartiles of the LoC distribution but found general support for the linear interaction model discussed here.
} 
We find that the impact of shocks vary substantially depending on an individual's LoC. For men whose LoC is $1 \mathrm{SD}$ higher (more internal) than the average man in the sample, crime victimization has a smaller and only transitory impact on mental health and life satisfaction. For example, the average immediate impact of crime victimization on mental health for men is -0.27 (from Table 2). The corresponding coefficient in Table 4 is 0.136 , suggesting that the immediate deterioration in mental health for men with a $1 \mathrm{SD}$ higher LoC score is only 0.13 of an SD $(-0.27+0.136)$. The moderating effect of internal LoC on life satisfaction and relationship prospects is even more dramatic. Men who are 1 SD more internal experience an immediate decline of only a 0.05 of an SD $(-0.25+0.199)$ in life satisfaction compared to the mean impact of -0.25 of a SD (Table 2$)$. Internal LoC completely reverses the medium and long-term impacts of crime victimization on relationship prospects.

An internal LoC also cushions men against the shock of a serious personal illness or injury. For these men, the magnitude of the short-run decline in mental health is smaller by about a third, in overall life satisfaction by nearly two-fifths and in employment prospects by over two-fifths, compared to the corresponding mean impacts in Table 2. Temporal impacts on income and relationship prospects also indicate a moderating role for internal LoC, but these effects are not statistically significant.

The interaction effects for women reveal a different pattern. Women whose LoC score is 1 SD higher (more internal LoC) than that of the woman with the average LoC, experience a bigger immediate deterioration in mental health and relationship prospects from crime victimization. The current year declines are bigger in magnitude by over one-fourth and nearly one-half for the two outcomes respectively, compared to the average effects in Table 3. For relationship prospects, the short-term impact (one year after the event) is also worse.

Summers-Effler (2004) argues that in regard to problems arising from asymmetric power relationships - relationships characterized by physical or psychological abuse, for example women with internal LoC are likely to behave in a manner that preserves the status quo. This is one way in which an internal LoC, perversely perhaps, gives them a feeling of limited control over their subordinate position in the relationship. Our results are broadly consistent with this hypothesis.

There is no clear pattern in the influence of LoC on the impacts from a serious physical illness/injury. 
The immediate impact of this shock on physical health is worse for women with a more internal LoC, compared to the average impact in Table 3. In the longer term however (four or more years after experiencing a serious physical illness or injury), having a more internal LoC appears to improve physical health and relationship outcomes for women.

As noted previously, one of the consequences of having an internal LoC is the desire to control ones environment. This prompts individuals of this type to be proactive in taking steps in advance of an event, to control its impact on their wellbeing (Folkman, 1984). This type of behavior is known as 'preventive coping, as opposed to "passive coping whereby individuals react to the event after it occurs. Interestingly, the results Tables 4 and 5 also reveal that interacting each shock with the LoC eliminates all anticipation effects, a result consistent with the hypothesized effect of control on behaviors.

\section{Conclusions}

In this paper, we use eleven waves of longitudinal data from the nationally representative Household, Income and Labour Dynamics of Australia (HILDA) survey to examine whether having an internal locus of control (LoC) helps people manage the consequences of two mainly unanticipated negative shocks: being a crime victim and experiencing a serious illness or injury. We compliment and extend the previous literature by examining the impact of these shocks and the moderating influence of LoC on multiple measures of affective wellbeing (AWB), cognitive wellbeing (CWB) and traditional socioeconomic outcomes. We also examine heterogeneity in these impacts by gender.

For men, we find that being the victim of a crime or suffering from a serious illness or injury has smaller effects on subjective wellbeing when they have more internal LoC. This is true for both AWB and CWB measures, but is stronger for AWB as measured by the SF-36 mental health domain. On the other hand, while both negative shocks lead to large long-run declines in income, this is no smaller for more internal men. Hence, it appears that men who are more internal feel better about similar circumstances than those who are more external.

For women, we find evidence that an internal LoC can be bad for coping. For example, being the victim of a violent crime has larger negative impacts on AWB and socioeconomic outcomes 
(in particular, marital status) for women with more internal LoC. This is also true for short-run impact of a serious illness or injury on physical health. In some circumstances, it appears to be easier for women to cope with unexpected negative shocks if they feel circumstances are outside their control.

The gender differences in the influence of locus of control on moderating the impacts of shocks on health and wellbeing are noteworthy. Economists have been slow to incorporate insights from the psychology literature on the possible sources of heterogeneity in adaptation. The generally negative impacts of an internal LoC on women's ability to cope with shocks are consistent with the findings of Burish et al. (1984), who emphasize that in situations where the possibility of exercising control to alter or improve outcomes is limited, having an external LoC might be advantageous to wellbeing. ${ }^{17}$ A different interpretation would be that women who like to exercise more control over their lives tend to blame themselves for the negative events that happen to them.

More generally, Folkman and Lazarus (1980) contend that the coping process is mediated by cognitive appraisal, which involves an assessment of the specific situation generating the stress and what can be done about it. Thus, an individual's generalized perception of control (internal/external) can differ from their appraisal of control over a specific situation, and both are called into play when faced with a stressful event. By implication, the impact of a shock on adaptation is likely to vary by type of shock, even after accounting for the generalized beliefs regarding control (Folkman, 1984). These are valuable and important insights, and need further evaluation by economists.

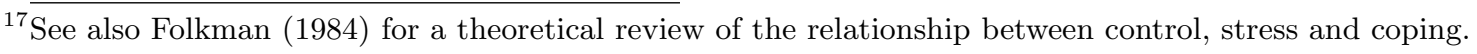




\section{References}

ABS (2005): "Personal Safety Survey," Report, Australian Bureau of Statistics.

Ballas, D., And D. Dorling (2007): "Measuring the Impact of Major Life Events upon Happiness," International Journal of Epidemiology, 36, 1244-1252.

BandurA, A. (1992): "A Social Cognitive Approach to the Exercise of Control over AIDS Infection," in Adolescents and AIDS: A Generation in Jeopardy, pp. 89-116. Sage Publications, Inc.

Barrick, M. R., And M. K. Mount (1991): "The Big Five Personality Dimensions and Job Performance: A Meta-Analysis," Personnel Psychology, 44(1), 1-26.

Borghans, L., A. L. Duckworth, J. J. Heckman, and B. Ter Weel (2008): "The Economics and Psychology of Personality Traits," Journal of Human Resources, 43(4), 972-1059.

Buddelmeyer, H., and N. Powdthavee (2016): "Can Having Internal Locus of Control Insure Against Negative Shocks? Psychological Evidence from Panel Data," Journal of Economic Behavior $\&$ Organization, 122, 88-109.

Burish, T. G., M. P. Carey, K. A. Wallston, M. J. Stein, R. N. Jamison, and J. N. LyLes (1984): "Health Locus of Control and Chronic Disease: An External Orientation may be Advantageous," Journal of Social and Clinical Psychology, 2(4), 326-332.

Carver, C. S., M. F. Scheier, and J. K. Weintraub (1989): “Assessing coping strategies: a theoretically based approach," Journal of Personality and Social Psychology, 56(2), 267.

Clark, A., E. Diener, Y. Georgellis, and R. E. Lucas (2008): "Lags And Leads in Life Satisfaction: a Test of the Baseline Hypothesis," Economic Journal, 118(529), F222-F243.

Clark, A., Y. Georgellis, and P. Sanfey (2001): "Scarring: The Psychological Impact of Past Unemployment," Economica, 68(270), 221-241.

Cobb-Clark, D. A., And S. Schurer (2013): "Two Economists' Musings on the Stability of Locus of Control," The Economic Journal, 123(570), F358-F400. 
Coleman, M., and T. DeLeire (2003): "An Economic Model of Locus of Control and the Human Capital Investment Decision," Journal of Human Resources, 38(3), 701-721.

Etilé, F., P. Frijters, D. Johnston, And M. Shields (2014): "Mental Health Resilience: Which Childhood Circumstances Matter," Paris School of Economics, mimeo.

Folkman, S. (1984): "Personal Control and Stress and Coping Processes: A Theoretical Analysis.," Journal of Personality and Social Psychology, 46(4), 839-852.

Folkman, S., And R. S. Lazarus (1980): "An Analysis of Coping in a Middle-Aged Community Sample," Journal of Health and Social Behavior, pp. 219-239.

Frederick, S., and G. Loewenstein (1999): "Hedonic adaptation," in Well-Being: The Foundations of Hedonic Psychology, pp. 302-329. Russell Sage Foundation.

Frijters, P., D. W. Johnston, and M. A.Shields (2011): "Life Satisfaction Dynamics with Quarterly Life Event Data," The Scandinavian Journal of Economics, 113(1), 190-211.

Gatz, M., and M. J. Karel (1993): "Individual Change in Perceived Control over 20 Years," International Journal of Behavioral Development, 16(2), 305-322.

Greenglass, E. R. (1988): "Type A Behaviour and Coping Strategies in Female and Male Supervisors," Applied Psychology, 37(3), 271-288.

Heckman, J. J., J. Stixrud, and S. Urzua (2006): "The Effects of Cognitive and Noncognitive Abilities on Labor Market," Journal of Labor Economics, 24(3), 411-482.

Jakšić, N., L. Brajković, E. Ivezić, R. Topić, and M. Jakovljević (2012): "The Role of Personality Traits in Posttraumatic Stress Disorder (PTSD)," Psychiatria Danubina, 24(3.), 256-266.

Kahneman, D., And A. Deaton (2010): "High Income Improves Evaluation of Life but not Emotional Well-Being," Proceedings of the National Academy of Sciences, 107(38), 16489-16493.

Kim-Prieto, C., E. Diener, M. Tamir, C. Scollon, and M. Diener (2005): "Integrating the Diverse Definitions of Happiness: A Time-Sequential Framework of Subjective Well-Being," Journal of Happiness Studies, 6(3), 261-300. 
Lengua, L. J., and E. A. Stormshak (2000): "Gender, Gender Roles, and Personality: Gender Differences in the Prediction of Coping and Psychological Symptoms," Sex Roles, 43(11-12), $787-820$.

Lindeboom, M., F. Portrait, and G. J. van den Berg (2002): "An Econometric Analysis of the Mental-Health Effects of Major Events in the Life of Older Individuals," Health Economics, $11,505-520$.

Lucas, R. E., A. Clark, Y. Georgellis, and E. Diener (2004): "Unemployment Alters the Set Point for Life Satisfaction," Psychological Science, 15(1), 8-13.

Luhmann, M., M. Eid, W. Hofmann, and R. E. Lucas (2012): "Subjective Well-Being and Adaptation to Life Events: A Meta-Analysis," Journal of Personality and Social Psychology, $102(3), 592-615$.

Mahuteau, S., and R. Zhu (2015): "Crime Victimisation and Subjective Well-Being: Panel Evidence From Australia," Health economics.

Mazure, C. M., M. L. Bruce, P. K. Maciejewski, and S. C. Jacobs (2000): "Adverse Life Events and Cognitive-Personality Characteristics in the Prediction of Major Depression and Antidepressant Response," American Journal of Psychiatry.

Mervin, M. C., And P. Frijters (2014): "Is Shared Misery Double Misery?," Social Science $\&$ Medicine, 107, 68-77.

Powdthavee, N. (2009): "What Happens to People Before and After Disability? Focusing Effects, Lead Effects, and Adaptation to Different Areas of Life," Social Science and Medicine, 69(529), $1834-1844$.

Randall, T. M., and M. Desrosiers (1980): "Measurement of Supernatural Belief: Sex Differences and Locus of Control," Journal of Personality Assessment, 44(5), 493-498.

Rotter, J. B. (1966): "Generalized Expectancies for Internal versus External Control of Reinforcement.," Psychological Monographs: General and Applied, 80(1), 1-28.

Seixas, A. A., C. James, G. Jean-Louis, M. Butler, F. Zizi, and A. Gardner (2015): "The Mediating Effects of Social Support and Locus of Control on the Relationship between 
Post-Traumatic Stress and Depressive Symptoms in a Jamaican University Sample," Journal of depression $\mathscr{E}$ anxiety, 4(3).

Specht, J., B. Egloff, and S. Schmukle (2011): "The Benefits of Believing in Chance or Fate: External Locus of Control as a Protective Factor for Coping with the Death of a Spouse," Social Psychological and Personality Science, 2(2), 132-137.

Steinlauf, B. (1979): "Problem-Solving Skills, Locus of Control, and The Contraceptive Effectiveness of Young Women," Child Development, pp. 268-271.

Strickland, B. R. (1978): "Internal-External Expectancies and Health-Related Behaviors," Journal of Consulting and Clinical Psychology, 46(6), 1192-1211.

Summers-Effler, E. (2004): "Defensive Strategies: The Formation and Social Implications of Patterned Self-Destructive Behavior," Advances in Group Processes, 21, 309-325. 
Table 1: Differences in Characteristics by Whether Individuals Experience Shocks

\begin{tabular}{|c|c|c|c|c|c|c|}
\hline & $\begin{array}{c}\text { Never Crime Victim } \\
\text { or Seriously Ill }\end{array}$ & $\begin{array}{l}\text { Ever Victim of } \\
\text { Violent Crime }\end{array}$ & $\begin{array}{c}\text { Ever Had Serious } \\
\text { Illness }\end{array}$ & $\begin{array}{l}\text { Never Crime Victim } \\
\text { or Seriously Ill }\end{array}$ & $\begin{array}{l}\text { Ever Victim of } \\
\text { Violent Crime }\end{array}$ & $\begin{array}{c}\text { Ever Had Serious } \\
\text { Illness }\end{array}$ \\
\hline & & Male & & & Female & \\
\hline Victim of Violent Crime & & $13.7 \%$ & $1.5 \%$ & & $15.1 \%$ & $1.5 \%$ \\
\hline Had Serious Illness/Injury & & $10.2 \%$ & $17.2 \%$ & & $10.9 \%$ & $17.0 \%$ \\
\hline Overall Physical Health & 0.32 & 0.11 & -0.11 & 0.29 & -0.04 & -0.23 \\
\hline Overall Mental Health & 0.18 & -0.29 & -0.07 & 0.09 & -0.60 & -0.23 \\
\hline Overall Life Satisfaction & -0.03 & -0.39 & -0.20 & 0.07 & -0.43 & -0.15 \\
\hline Satisfaction w/ Relationships & 0.02 & -0.44 & -0.11 & 0.02 & -0.62 & -0.16 \\
\hline Employed & $90.6 \%$ & $81.3 \%$ & $82.7 \%$ & $74.0 \%$ & $63.6 \%$ & $67.3 \%$ \\
\hline Real Individual Income & 0.65 & 0.27 & 0.45 & 0.00 & -0.07 & -0.05 \\
\hline Married/De-Facto & $81.2 \%$ & $62.2 \%$ & $77.5 \%$ & $78.5 \%$ & $59.9 \%$ & $72.9 \%$ \\
\hline Locus of Control & 0.19 & -0.19 & -0.05 & 0.15 & -0.28 & -0.10 \\
\hline Age & 43.1 & 40.3 & 45.9 & 43.1 & 40.5 & 45.8 \\
\hline Did Not Finish High School & $19.5 \%$ & $20.2 \%$ & $24.2 \%$ & $30.3 \%$ & $31.6 \%$ & $33.3 \%$ \\
\hline High School Graduate & $11.9 \%$ & $13.7 \%$ & $9.9 \%$ & $14.2 \%$ & $14.1 \%$ & $12.2 \%$ \\
\hline Non-University Degree & $39.9 \%$ & $45.8 \%$ & $41.1 \%$ & $25.0 \%$ & $32.7 \%$ & $25.9 \%$ \\
\hline Bachelor Degree or Higher & $28.7 \%$ & $20.3 \%$ & $24.8 \%$ & $30.5 \%$ & $21.6 \%$ & $28.6 \%$ \\
\hline$\%$ of Sample by Gender & $61.9 \%$ & $6.5 \%$ & $35.0 \%$ & $64.7 \%$ & $5.6 \%$ & $32.7 \%$ \\
\hline Observations & 20,099 & 2,096 & 11,348 & 24,000 & 2,083 & 12,143 \\
\hline Individuals & 3,019 & 298 & 1,474 & 3,448 & 270 & 1,528 \\
\hline
\end{tabular}

Note: Individual income is in 2001 dollars and all outcome variables, besides employment and married/de-facto, and locus of control are standardised to mean zero. 
Table 2: Fixed Effects Estimates of the Impact of Shocks on Health and Wellbeing on Men

\begin{tabular}{|c|c|c|c|c|c|c|c|}
\hline & $\begin{array}{c}\text { Overall Physical } \\
\text { Health }\end{array}$ & $\begin{array}{c}\text { Overall Mental } \\
\text { Health }\end{array}$ & $\begin{array}{l}\text { Overall Life } \\
\text { Satisfaction }\end{array}$ & $\begin{array}{l}\text { Satisfaction w/ } \\
\text { Relationships }\end{array}$ & Employed & Individual Income & $\begin{array}{l}\text { Married or in De- } \\
\text { Facto Relationship }\end{array}$ \\
\hline \multicolumn{8}{|c|}{ Victim of Violent Crime } \\
\hline \multirow[t]{2}{*}{ Year Prior } & 0.00201 & -0.0972 & -0.0859 & -0.0213 & -0.00152 & -0.0406 & -0.0142 \\
\hline & $(0.046)$ & $(0.070)$ & $(0.071)$ & $(0.057)$ & $(0.018)$ & $(0.035)$ & $(0.023)$ \\
\hline \multirow[t]{2}{*}{ Current Year } & -0.0174 & $-0.270 * * *$ & $-0.250 * * *$ & $-0.181 * * *$ & -0.021 & -0.0414 & $-0.0445^{* *}$ \\
\hline & $(0.048)$ & $(0.074)$ & $(0.067)$ & $(0.064)$ & $(0.020)$ & $(0.038)$ & $(0.020)$ \\
\hline \multirow[t]{2}{*}{ One Year Later } & 0.00112 & $-0.127 *$ & -0.0821 & $-0.131 * *$ & -0.0141 & -0.0251 & $-0.0528 * *$ \\
\hline & $(0.043)$ & $(0.073)$ & $(0.072)$ & $(0.061)$ & $(0.022)$ & $(0.042)$ & $(0.022)$ \\
\hline \multirow[t]{2}{*}{ 2-3 Years Later } & $-0.117 * *$ & 0.00895 & $-0.133^{* *}$ & $-0.199 * * *$ & 0.00282 & $-0.0689 * *$ & $-0.0763 * * *$ \\
\hline & $(0.050)$ & $(0.069)$ & $(0.064)$ & $(0.064)$ & $(0.022)$ & $(0.034)$ & $(0.029)$ \\
\hline \multirow[t]{2}{*}{ 4+ Years Later } & 0.0231 & 0.0284 & -0.0372 & 0.000531 & 0.0061 & $-0.124 * *$ & -0.0265 \\
\hline & $(0.048)$ & $(0.072)$ & $(0.070)$ & $(0.073)$ & $(0.023)$ & $(0.050)$ & $(0.035)$ \\
\hline \multicolumn{8}{|c|}{ Experienced Serious Personal Illness or Injury } \\
\hline \multirow[t]{2}{*}{ Year Prior } & $-0.0751 * * *$ & $-0.0764 * * *$ & $-0.0454 * *$ & -0.0145 & 0.00347 & -0.0281 & -0.00218 \\
\hline & $(0.018)$ & $(0.020)$ & $(0.022)$ & $(0.020)$ & $(0.008)$ & $(0.019)$ & $(0.006)$ \\
\hline \multirow[t]{2}{*}{ Current Year } & $-0.528 * * *$ & $-0.222 * * *$ & $-0.186^{* * *}$ & $-0.0546 * * *$ & $-0.0509 * * *$ & 0.0228 & $-0.0105^{*}$ \\
\hline & $(0.023)$ & $(0.022)$ & $(0.022)$ & $(0.021)$ & $(0.008)$ & $(0.025)$ & $(0.006)$ \\
\hline \multirow[t]{2}{*}{ One Year Later } & $-0.122 * * *$ & $-0.0542 * *$ & $-0.0862 * * *$ & -0.0315 & $-0.0349 * * *$ & $-0.0761 * * *$ & -0.0111 \\
\hline & $(0.021)$ & $(0.022)$ & $(0.024)$ & $(0.023)$ & $(0.009)$ & $(0.022)$ & $(0.007)$ \\
\hline \multirow[t]{2}{*}{ 2-3 Years Later } & $-0.125 * * *$ & $-0.0397 *$ & $-0.0922 * * *$ & -0.032 & $-0.0163 *$ & $-0.0729 * * *$ & -0.0133 \\
\hline & $(0.020)$ & $(0.022)$ & $(0.023)$ & $(0.022)$ & $(0.009)$ & $(0.025)$ & $(0.008)$ \\
\hline \multirow[t]{2}{*}{ 4+ Years Later } & $-0.111 * * *$ & -0.0348 & $-0.0698 * *$ & $-0.0639 * *$ & $-0.0293 * *$ & $-0.0950 * * *$ & 0.00805 \\
\hline & $(0.024)$ & $(0.026)$ & $(0.028)$ & $(0.027)$ & $(0.012)$ & $(0.031)$ & $(0.012)$ \\
\hline Individuals & 4,642 & 4,642 & 4,642 & 4,642 & 4,642 & 4,642 & 4,642 \\
\hline Observations & 32,449 & 32,449 & 32,449 & 32,449 & 32,449 & 32,449 & 32,449 \\
\hline
\end{tabular}


Table 3: Fixed Effects Estimates of the Impact of Shocks on Health and Wellbeing on Women

\begin{tabular}{|c|c|c|c|c|c|c|c|}
\hline & $\begin{array}{c}\text { Overall Physical } \\
\text { Health }\end{array}$ & $\begin{array}{c}\text { Overall Mental } \\
\text { Health }\end{array}$ & $\begin{array}{l}\text { Overall Life } \\
\text { Satisfaction }\end{array}$ & $\begin{array}{l}\text { Satisfaction w/ } \\
\text { Relationships }\end{array}$ & Employed & Individual Income & $\begin{array}{l}\text { Married or in De- } \\
\text { Facto Relationship }\end{array}$ \\
\hline \multicolumn{8}{|c|}{ Victim of Violent Crime } \\
\hline \multirow[t]{2}{*}{ Year Prior } & -0.0503 & $-0.225 * * *$ & $-0.194 * * *$ & $-0.124 * *$ & -0.00483 & 0.02 & 0.0411 \\
\hline & $(0.045)$ & $(0.072)$ & $(0.067)$ & $(0.054)$ & $(0.023)$ & $(0.048)$ & $(0.026)$ \\
\hline \multirow[t]{2}{*}{ Current Year } & 0.0642 & $-0.532 * * *$ & $-0.351 * * *$ & $-0.438 * * *$ & -0.0187 & -0.00119 & $-0.105 * * *$ \\
\hline & $(0.049)$ & $(0.074)$ & $(0.069)$ & $(0.059)$ & $(0.024)$ & $(0.026)$ & $(0.029)$ \\
\hline \multirow[t]{2}{*}{ One Year Later } & 0.0519 & $-0.243 * * *$ & $-0.113^{*}$ & $-0.106^{*}$ & -0.024 & 0.0133 & -0.0412 \\
\hline & $(0.053)$ & $(0.069)$ & $(0.059)$ & $(0.063)$ & $(0.025)$ & $(0.043)$ & $(0.026)$ \\
\hline \multirow[t]{2}{*}{ 2-3 Years Later } & -0.0212 & $-0.206^{* * *}$ & -0.0676 & $-0.184 * * *$ & -0.0186 & 0.00282 & $-0.0794 * * *$ \\
\hline & $(0.050)$ & $(0.072)$ & $(0.057)$ & $(0.056)$ & $(0.028)$ & $(0.029)$ & $(0.028)$ \\
\hline \multirow[t]{2}{*}{ 4+ Years Later } & 0.00799 & -0.0852 & -0.0668 & -0.0906 & 0.0288 & 0.0287 & $-0.0940 * * *$ \\
\hline & $(0.048)$ & $(0.075)$ & $(0.077)$ & $(0.076)$ & $(0.031)$ & $(0.035)$ & $(0.036)$ \\
\hline \multicolumn{8}{|c|}{ Experienced Serious Personal Illness or Injury } \\
\hline \multirow[t]{2}{*}{ Year Prior } & $-0.161 * * *$ & $-0.0919 * * *$ & $-0.0837 * * *$ & -0.0157 & 0.00533 & -0.000938 & -0.00987 \\
\hline & $(0.021)$ & $(0.023)$ & $(0.023)$ & $(0.020)$ & $(0.009)$ & $(0.012)$ & $(0.006)$ \\
\hline \multirow[t]{2}{*}{ Current Year } & $-0.604 * * *$ & $-0.234 * * *$ & $-0.204 * * *$ & -0.00762 & $-0.0437 * * *$ & $-0.0230 *$ & -0.000707 \\
\hline & $(0.024)$ & $(0.025)$ & $(0.023)$ & $(0.019)$ & $(0.009)$ & $(0.012)$ & $(0.006)$ \\
\hline \multirow[t]{2}{*}{ One Year Later } & $-0.151 * * *$ & $-0.0625 * *$ & $-0.0470^{*}$ & -0.0216 & $-0.0217 * *$ & $-0.0425 * * *$ & 0.0035 \\
\hline & $(0.021)$ & $(0.025)$ & $(0.024)$ & $(0.021)$ & $(0.010)$ & $(0.012)$ & $(0.007)$ \\
\hline \multirow[t]{2}{*}{ 2-3 Years Later } & $-0.158 * * *$ & -0.0357 & $-0.0482 * *$ & 0.00428 & $-0.0176^{*}$ & $-0.0536 * * *$ & 0.00761 \\
\hline & $(0.022)$ & $(0.024)$ & $(0.023)$ & $(0.021)$ & $(0.011)$ & $(0.014)$ & $(0.008)$ \\
\hline \multirow[t]{2}{*}{ 4+ Years Later } & $-0.127 * * *$ & -0.0381 & -0.00443 & 0.0249 & $-0.0304 * *$ & -0.0225 & -0.00414 \\
\hline & $(0.026)$ & $(0.028)$ & $(0.030)$ & $(0.027)$ & $(0.015)$ & $(0.020)$ & $(0.012)$ \\
\hline Individuals & 5,103 & 5,103 & 5,103 & 5,103 & 5,103 & 5,103 & 5,103 \\
\hline Observations & 37,100 & 37,100 & 37,100 & 37,100 & 37,100 & 37,100 & 37,100 \\
\hline
\end{tabular}


Table 4: Does the Impact of Shocks on Men Depend on their Locus of Control?

\begin{tabular}{|c|c|c|c|c|c|c|c|}
\hline & $\begin{array}{c}\text { Overall Physical } \\
\text { Health } \\
\end{array}$ & $\begin{array}{c}\text { Overall Mental } \\
\text { Health } \\
\end{array}$ & $\begin{array}{l}\text { Overall Life } \\
\text { Satisfaction }\end{array}$ & $\begin{array}{c}\text { Satisfaction w/ } \\
\text { Relationships } \\
\end{array}$ & Employed & Individual Income & $\begin{array}{l}\text { Married or in De- } \\
\text { Facto Relationship }\end{array}$ \\
\hline \multicolumn{8}{|c|}{ Victim of Violent Crime interacted with Standardised Locus of Control } \\
\hline \multirow[t]{2}{*}{ Year Prior } & -0.0428 & 0.0973 & 0.0416 & 0.0387 & -0.0152 & -0.0206 & 0.0391 \\
\hline & $(0.057)$ & $(0.076)$ & $(0.071)$ & $(0.068)$ & $(0.019)$ & $(0.049)$ & $(0.031)$ \\
\hline \multirow[t]{2}{*}{ Current Year } & -0.047 & $0.136 * *$ & $0.199 * * *$ & 0.077 & -0.00654 & -0.0324 & 0.0304 \\
\hline & $(0.052)$ & $(0.059)$ & $(0.071)$ & $(0.081)$ & $(0.020)$ & $(0.043)$ & $(0.024)$ \\
\hline \multirow[t]{2}{*}{ One Year Later } & 0.0214 & 0.082 & 0.0537 & 0.0014 & 0.00792 & -0.0664 & 0.00241 \\
\hline & $(0.052)$ & $(0.072)$ & $(0.072)$ & $(0.059)$ & $(0.025)$ & $(0.050)$ & $(0.024)$ \\
\hline \multirow[t]{2}{*}{ 2-3 Years Later } & 0.0405 & -0.0211 & 0.0525 & 0.0749 & 0.0298 & 0.0226 & $0.0833 * *$ \\
\hline & $(0.060)$ & $(0.067)$ & $(0.070)$ & (0.094) & $(0.025)$ & $(0.034)$ & $(0.033)$ \\
\hline \multirow[t]{2}{*}{ 4+ Years Later } & 0.00611 & 0.0669 & -0.0147 & -0.0287 & -0.00138 & 0.00198 & $0.0696^{*}$ \\
\hline & $(0.060)$ & $(0.080)$ & $(0.083)$ & $(0.094)$ & $(0.033)$ & $(0.056)$ & $(0.038)$ \\
\hline Joint Significance VC & {$[0.713]$} & {$[0.084]$} & {$[0.043]$} & {$[0.653]$} & {$[0.709]$} & [0.429] & {$[0.055]$} \\
\hline \multicolumn{8}{|c|}{ Experienced Serious Personal Illness or Injury interacted with Standardised Locus of Control } \\
\hline \multirow[t]{2}{*}{ Year Prior } & 0.0125 & 0.0164 & 0.0156 & $0.0398^{*}$ & 0.00383 & $-0.0322^{*}$ & 0.00207 \\
\hline & $(0.021)$ & $(0.025)$ & $(0.029)$ & $(0.024)$ & $(0.009)$ & $(0.018)$ & $(0.008)$ \\
\hline \multirow[t]{2}{*}{ Current Year } & -0.0155 & $0.0703 * *$ & $0.0700 * *$ & 0.038 & $0.0210 * *$ & 0.0448 & 0.00453 \\
\hline & $(0.026)$ & $(0.029)$ & $(0.030)$ & $(0.027)$ & $(0.010)$ & $(0.029)$ & $(0.008)$ \\
\hline \multirow[t]{2}{*}{ One Year Later } & 0.0353 & 0.0113 & -0.00176 & $0.0510^{*}$ & $0.0187^{*}$ & 0.00411 & 0.0125 \\
\hline & $(0.024)$ & $(0.027)$ & $(0.030)$ & $(0.028)$ & $(0.010)$ & $(0.022)$ & $(0.008)$ \\
\hline \multirow[t]{2}{*}{ 2-3 Years Later } & 0.0295 & 0.0174 & 0.0209 & 0.032 & $0.0200 * *$ & 0.00752 & 0.0065 \\
\hline & $(0.022)$ & $(0.025)$ & $(0.033)$ & $(0.026)$ & $(0.010)$ & $(0.028)$ & $(0.009)$ \\
\hline \multirow[t]{2}{*}{ 4+ Years Later } & 0.0129 & -0.00778 & -0.0229 & 0.0412 & 0.000538 & 0.0308 & 0.0154 \\
\hline & $(0.028)$ & $(0.031)$ & $(0.039)$ & $(0.031)$ & $(0.013)$ & $(0.031)$ & $(0.013)$ \\
\hline Joint Significance SI & {$[0.367]$} & {$[0.166]$} & {$[0.103]$} & {$[0.290]$} & {$[0.082]$} & {$[0.219]$} & {$[0.542]$} \\
\hline Joint Significance ALL & {$[0.553]$} & {$[0.042]$} & {$[0.022]$} & {$[0.567]$} & {$[0.192]$} & {$[0.282]$} & {$[0.116]$} \\
\hline Individuals & 4,642 & 4,642 & 4,642 & 4,642 & 4,642 & 4,642 & 4,642 \\
\hline Observations & 32,449 & 32,449 & 32,449 & 32,449 & 32,449 & 32,449 & 32,449 \\
\hline
\end{tabular}


Table 5: Does the Impact of Shocks on Women Depend on their Locus of Control?

\begin{tabular}{|c|c|c|c|c|c|c|c|}
\hline & $\begin{array}{c}\text { Overall Physical } \\
\text { Health }\end{array}$ & $\begin{array}{c}\text { Overall Mental } \\
\text { Health }\end{array}$ & $\begin{array}{l}\text { Overall Life } \\
\text { Satisfaction }\end{array}$ & $\begin{array}{l}\text { Satisfaction w/ } \\
\text { Relationships }\end{array}$ & Employed & Individual Income & $\begin{array}{l}\text { Married or in De- } \\
\text { Facto Relationship }\end{array}$ \\
\hline \multicolumn{8}{|c|}{ Victim of Violent Crime interacted with Standardised Locus of Control } \\
\hline \multirow[t]{2}{*}{ Year Prior } & 0.0226 & 0.0393 & -0.0264 & -0.00406 & 0.0044 & 0.0373 & -0.00711 \\
\hline & $(0.046)$ & $(0.059)$ & $(0.067)$ & $(0.046)$ & $(0.026)$ & $(0.043)$ & $(0.025)$ \\
\hline \multirow[t]{2}{*}{ Current Year } & $0.0818^{*}$ & $-0.138 * *$ & -0.0883 & -0.0532 & 0.032 & 0.037 & $-0.0510 * *$ \\
\hline & $(0.048)$ & $(0.069)$ & $(0.070)$ & $(0.049)$ & $(0.026)$ & $(0.030)$ & $(0.025)$ \\
\hline \multirow[t]{2}{*}{ One Year Later } & 0.0719 & 0.0219 & 0.0205 & -0.0342 & 0.00142 & 0.00319 & $-0.0469 *$ \\
\hline & $(0.055)$ & $(0.070)$ & $(0.061)$ & $(0.060)$ & $(0.029)$ & $(0.035)$ & $(0.026)$ \\
\hline \multirow[t]{2}{*}{ 2-3 Years Later } & 0.0156 & -0.0643 & -0.0476 & 0.0157 & -0.00681 & 0.00371 & 0.00414 \\
\hline & $(0.052)$ & $(0.075)$ & $(0.067)$ & $(0.051)$ & $(0.035)$ & $(0.029)$ & $(0.028)$ \\
\hline \multirow[t]{2}{*}{ 4+ Years Later } & 0.018 & -0.0588 & -0.0251 & -0.0271 & -0.0283 & 0.0388 & 0.0155 \\
\hline & $(0.048)$ & $(0.065)$ & $(0.082)$ & $(0.070)$ & $(0.034)$ & $(0.039)$ & $(0.040)$ \\
\hline Joint Significance VC & {$[0.394]$} & {$[0.287]$} & {$[0.681]$} & {$[0.714]$} & {$[0.411]$} & {$[0.663]$} & [0.093] \\
\hline \multicolumn{8}{|c|}{ Experienced Serious Personal Illness or Injury interacted with Standardised Locus of Control } \\
\hline \multirow[t]{2}{*}{ Year Prior } & -0.00784 & 0.0216 & 0.0365 & -0.0159 & -0.0056 & 0.00272 & -0.00145 \\
\hline & $(0.024)$ & $(0.025)$ & $(0.027)$ & $(0.023)$ & $(0.010)$ & $(0.012)$ & $(0.007)$ \\
\hline \multirow[t]{2}{*}{ Current Year } & $-0.0443 *$ & 0.015 & -0.00898 & 0.0293 & 0.00218 & -0.00772 & 0.0101 \\
\hline & $(0.026)$ & $(0.026)$ & $(0.029)$ & $(0.023)$ & $(0.010)$ & $(0.011)$ & $(0.007)$ \\
\hline \multirow[t]{2}{*}{ One Year Later } & 0.00987 & $0.0429 *$ & -0.00726 & -0.0196 & 0.00506 & 0.00384 & 0.00485 \\
\hline & $(0.024)$ & $(0.025)$ & $(0.029)$ & $(0.022)$ & $(0.011)$ & $(0.012)$ & $(0.007)$ \\
\hline \multirow[t]{2}{*}{ 2-3 Years Later } & 0.00525 & -0.0052 & -0.0169 & 0.0132 & -0.0167 & 0.0125 & 0.0117 \\
\hline & $(0.026)$ & $(0.025)$ & $(0.029)$ & $(0.023)$ & $(0.012)$ & $(0.012)$ & $(0.008)$ \\
\hline \multirow[t]{2}{*}{ 4+ Years Later } & $0.0583 * *$ & 0.0189 & -0.0179 & 0.000724 & 0.00929 & -0.0155 & $0.0372 * * *$ \\
\hline & $(0.028)$ & $(0.026)$ & $(0.034)$ & $(0.029)$ & $(0.016)$ & $(0.024)$ & $(0.014)$ \\
\hline Joint Significance SI & {$[0.044]$} & [0.475] & {$[0.973]$} & {$[0.434]$} & {$[0.270]$} & {$[0.522]$} & {$[0.059]$} \\
\hline Joint Significance ALL & {$[0.082]$} & {$[0.407]$} & {$[0.934]$} & {$[0.645]$} & {$[0.314]$} & {$[0.732]$} & {$[0.032]$} \\
\hline Individuals & 5,103 & 5,103 & 5,103 & 5,103 & 5,103 & 5,103 & 5,103 \\
\hline Observations & 37,100 & 37,100 & 37,100 & 37,100 & 37,100 & 37,100 & 37,100 \\
\hline
\end{tabular}


Table A1: Summary Statistics

\begin{tabular}{|c|c|c|c|c|}
\hline & $\begin{array}{l}\text { Full Prime- } \\
\text { Age Sample }\end{array}$ & $\begin{array}{l}\text { Valid Shock } \\
\text { Data Sample }\end{array}$ & $\begin{array}{l}\text { Also with } \\
\text { LoC Data }\end{array}$ & $\begin{array}{c}\text { Analysis } \\
\text { Sample }\end{array}$ \\
\hline Victim of Violent Crime & $1.14 \%$ & $0.85 \%$ & $0.87 \%$ & $0.87 \%$ \\
\hline Experienced Serious Personal Illness/Inju & $6.48 \%$ & $5.72 \%$ & $5.82 \%$ & $5.77 \%$ \\
\hline Overall Physical Health & 50.4 & 50.9 & 50.9 & 51.0 \\
\hline Overall Mental Health & 48.6 & 49.0 & 49.1 & 49.1 \\
\hline Overall Life Satisfaction & 7.77 & 7.83 & 7.83 & 7.83 \\
\hline Satisfaction with Relationships & 7.85 & 7.87 & 7.87 & 7.88 \\
\hline Employed & 0.77 & 0.78 & 0.78 & 0.79 \\
\hline Real Individual Income $(10,000 \mathrm{~s})$ & 4.05 & 4.16 & 4.17 & 4.21 \\
\hline Married or in De-Facto Relationship & $74.1 \%$ & $76.0 \%$ & $76.2 \%$ & $77.7 \%$ \\
\hline Standarised Locus of Control & 0.02 & 0.07 & 0.07 & 0.08 \\
\hline$\overline{\text { Age }}$ & 43.6 & 43.9 & 44.0 & 43.9 \\
\hline Sydney & $17.0 \%$ & $16.0 \%$ & $16.0 \%$ & $15.9 \%$ \\
\hline New South Wales / ACT & $15.0 \%$ & $15.2 \%$ & $15.3 \%$ & $15.3 \%$ \\
\hline Melbourne & $17.7 \%$ & $18.0 \%$ & $18.0 \%$ & $17.9 \%$ \\
\hline Victoria / Tasmania & $10.2 \%$ & $10.1 \%$ & $10.1 \%$ & $10.0 \%$ \\
\hline Brisbane & $9.3 \%$ & $9.5 \%$ & $9.5 \%$ & $9.6 \%$ \\
\hline Queensland & $11.6 \%$ & $11.8 \%$ & $11.8 \%$ & $11.9 \%$ \\
\hline South Australia & $9.0 \%$ & $9.0 \%$ & $9.0 \%$ & $9.0 \%$ \\
\hline Western Australia / Northern Territory & $10.3 \%$ & $10.4 \%$ & $10.4 \%$ & $10.4 \%$ \\
\hline$\overline{\text { Major City }}$ & $62.6 \%$ & $62.6 \%$ & $62.5 \%$ & $62.4 \%$ \\
\hline Inner Regional Australia & $24.3 \%$ & $24.5 \%$ & $24.6 \%$ & $24.6 \%$ \\
\hline Outer Regional and Remote Australia & $13.1 \%$ & $12.9 \%$ & $12.9 \%$ & $13.0 \%$ \\
\hline Did Not Finish High School & $28.5 \%$ & $27.1 \%$ & $27.1 \%$ & $26.6 \%$ \\
\hline High School Graduate & $12.7 \%$ & $12.5 \%$ & $12.4 \%$ & $12.4 \%$ \\
\hline Non-University Degree & $32.2 \%$ & $32.3 \%$ & $32.4 \%$ & $32.5 \%$ \\
\hline Bachelor Degree or Higher & $26.6 \%$ & $28.1 \%$ & $28.1 \%$ & $28.4 \%$ \\
\hline Year $=2001$ & $9.4 \%$ & & & \\
\hline Year $=2002$ & $8.6 \%$ & $9.8 \%$ & $9.3 \%$ & $8.9 \%$ \\
\hline Year $=2003$ & $8.3 \%$ & $9.4 \%$ & $9.6 \%$ & $9.4 \%$ \\
\hline Year $=2004$ & $8.0 \%$ & $9.1 \%$ & $9.3 \%$ & $9.3 \%$ \\
\hline Year $=2005$ & $8.1 \%$ & $9.0 \%$ & $9.0 \%$ & $9.1 \%$ \\
\hline Year $=2006$ & $8.1 \%$ & $9.0 \%$ & $9.0 \%$ & $9.2 \%$ \\
\hline Year $=2007$ & $8.0 \%$ & $8.7 \%$ & $8.9 \%$ & $8.9 \%$ \\
\hline Year $=2008$ & $8.0 \%$ & $8.5 \%$ & $8.5 \%$ & $8.7 \%$ \\
\hline Year $=2009$ & $8.2 \%$ & $8.8 \%$ & $8.8 \%$ & $8.8 \%$ \\
\hline Year $=2010$ & $8.3 \%$ & $9.2 \%$ & $9.2 \%$ & $9.4 \%$ \\
\hline Year $=2011$ & $8.4 \%$ & $9.2 \%$ & $9.4 \%$ & $9.4 \%$ \\
\hline Year $=2012$ & $8.4 \%$ & $9.2 \%$ & $9.0 \%$ & $8.9 \%$ \\
\hline Observations & 102,025 & 75,305 & 73,575 & 69,549 \\
\hline
\end{tabular}

